Article

\title{
Headspace Gas Chromatography-Mass Spectrometry for Volatile Components Analysis in Ipomoea Cairica (L.) Sweet Leaves: Natural Deep Eutectic Solvents as Green Extraction and Dilution Matrix
}

\author{
Wei Zhang and Xianrui Liang *(1) \\ Collaborative Innovation Center of Yangtze River Delta Region Green Pharmaceuticals, College of \\ Pharmaceutical Sciences, Zhejiang University of Technology, Hangzhou 310014, China; 15958100694@163.com \\ * Correspondence: liangxrvicky@zjut.edu.cn; Tel.: +86-5718-832-0420
}

Received: 9 May 2019; Accepted: 7 June 2019; Published: 11 June 2019

check for updates

\begin{abstract}
In this study, natural deep eutectic solvents (NADESs) were used as both the extraction and dilution matrix in static headspace gas chromatography-mass spectrometry (SHS-GC-MS) for the analysis of volatile components in Ipomoea cairica (L). Sweet (ICS) leaves. Six NADESs were prepared and the NADESs composed of choline chloride and glucose with a 1:1 molar ratio containing $15 \%$ water were preferred due to the better peak responses. A total of 77 volatiles in ICS leaves were detected and tentatively identified by mass spectral matching with the US National Institute of Standards and Technology (NIST, 2014) Mass Spectral Library and the retention index-assisted qualitative method. These 77 volatile components were mainly terpenoids, aromatics, and aliphatics. Among them, $\beta$-elemene, $\beta$-caryophyllene, $\alpha$-humulene, and 2, 4-di-tert-butylphenol were found to be the main components. This investigation verified that the use of NADESs is an efficient green extraction and dilution matrix of the SHS-GC-MS method for direct volatile component analysis of plant materials without extra extraction work.
\end{abstract}

Keywords: Ipomoea cairica (L.) Sweet leaves; natural deep eutectic solvents; static headspace gas chromatography-mass spectrometry; volatile components

\section{Introduction}

Plant volatiles are a series of low molecular weight lipophilic compounds derived from different biosynthetic pathways during plant growth [1]. The volatile components in the plant materials are usually produced for defensive strategies against biotic and abiotic stresses, contributing to the various antimicrobial and antioxidative properties [2-4]. These volatile components are often extracted as essential oils, which have a long history of applications in the pharmaceutical, agricultural, and cosmetic industries [5,6]. The bioactivities of essential oils are often greatly influenced by the chemical composition, which makes the chemical characterization of volatile components an important work [7-9]. Hence, there is still a lot of structural identification and bioactivity research work to do for the development and application of diverse natural plant materials.

Ipomoea cairica (L.) Sweet (ICS), belonging to the perennial herbaceous vines of the genus, sweet potato of convolvulacea, with a wide distribution nearly all over the world, is used worldwide as folk medicine [10-12]. Pharmacological activity research has also revealed that ICS has cytotoxic, larvicidal, anti-inflammatory, and antinociceptive activities [13-19]. The various bioactivities are relevant to the diverse components in ICS [20]. For example, larvicidal and antinociceptive activities have been demonstrated to be related to the volatile components in ICS [20]. However, the volatile components' profile of ICS has not been well explored. 
Static headspace gas chromatography mass spectrometry (SHS-GC-MS) is a powerful and efficient way to profile the composition of complex volatile components due to its effectiveness in simultaneous chromatographic separation and structural identification [21,22]. Compared to direct injection, SHS sampling is clean and convenient as a gas extraction technique for GC-MS analysis. Although SHS has been used as a mature technique for decades, the method's optimization work has never been terminated. One of the important works is exploring the superior dilution matrix. Except for the traditionally used dilution matrix of dimethyl sulfoxide (DMSO), dimethylacetamide (DMA), and water, many other high boiling solvents, such as paraffin and ionic liquids, have also been used as SHS matrix medium [23-26]. Recently, we successfully introduced another new type of green solvent natural deep eutectic solvents (NADESs) into SHS for the analysis of residue solvents in pharmaceuticals [27]. The NADESs exhibited many superiorities over the traditionally used matrix, with easy preparation, very low price and toxicity, biodegradability, and, most important of all, good sensitivity [28-31]. NADESs have also been demonstrated to be good solvents for the simultaneous extraction of hydrophilic and hydrophobic compounds from plant materials [32].

To further explore the application of NADESs as a green and friendly dilution matrix medium, volatile compounds in ICS leaves were analyzed by the SHS-GC-MS method in this study. The NADESs was used as both the extraction and dilution media. Six choline chloride based NADESs were prepared. The key SHS-GC parameters were optimized. Based on the optimized conditions, the structures of volatile components in ICS leaves were illustrated. The results of this study verified the feasibility of NADESs as a headspace extraction and dilution matrix in the analysis of volatile components from plant materials, and also provided useful information for the development and application of ICS in foods and medicals.

\section{Materials and Methods}

\subsection{Regents and Materials}

Leaves of ICS were collected from Meizhou, Guangdong and identified by Aichun Zhou in Zhejiang Agriculture and Forestry University. It was stored at $-4{ }^{\circ} \mathrm{C}$ until use. Levulinic acid (purity $\geq 99.0 \%$ ) were purchased from Aladdin Biochemical Co., Ltd. (Shanghai, China). Glucose (purity $\geq 98.0 \%$ ), citric acid (purity $\geq 99.5 \%$ ), maltose (purity $\geq 98.0 \%$ ), fructose (purity $\geq 98.0 \%$ ), and 1,4-butanediol (purity $\geq 99.0 \%$ ) were purchased from Sinopharm Chemical Reagent Co., Ltd. (Beijing, China). Choline chloride (purity $\geq 98.0 \%$ ) were purchased from Yuanye Biological Co., Ltd. (Shanghai, China). The reagents and chemicals used above were all of analytical grade. The HPLC-grade n-hexane (purity $\geq 95.0 \%$ ) was purchased from TEDIA (Cincinnati, $\mathrm{OH}, \mathrm{USA}$ ). The $\mathrm{C}_{7}-\mathrm{C}_{40} n$-alkane saturated alkane mixture $(1000 \mathrm{mg} / \mathrm{L})$ used as reference standards were purchased from Sigma-Aldrich Co., Ltd. (Shanghai, China).

\subsection{Preparation of NADESs}

NADESs were prepared by heating method [31]. The HBAs with different HBDs in different molar ratios were mixed in a conical flask with a cover and magnetically stirred at $85^{\circ} \mathrm{C}$ by a water bath until a homogeneous liquid formed. Standing at room temperature, NADES was completed if no solid precipitation occurred. The NADES-1,2,5 were composed of choline chloride and citric acid, glucose, and maltose with a 1:1 molar ratio. The NADES-3, 4 were composed of choline chloride and levulinic acid, 1,4-butanediol with 1:2 molar ratio. The NADES-6 was composed of choline chloride and fructose with a 2:1 molar ratio.

\subsection{Preparation of ICS Leaves Powder}

The ICS leaves were pulverized and sifted by an 80 mesh sieve. The powder was further triturated on a Retsch PM200 planetary ball mill (Retsch Inc., Haan, Germany) to obtain smaller particle size 
powder under optimal conditions. The optimized ball milling conditions were: The ball to powder weight ratio was 1:30, rotating speed was $300 \mathrm{rpm}$, and rotating time was $25 \mathrm{~min}$.

\subsection{SHS-GC-MS Analysis Conditions}

The SHS-GC-MS analysis was performed in an Agilent 7890B-5977A gas chromatograph-mass spectrometer equipped with an Agilent 7697A Headspace auto-sampler (Agilent Technologies Inc., Santa Clara, CA, USA). A J\&W capillary column HP-5 MS UI of $30 \mathrm{~m} \times 0.250 \mathrm{~mm}$ with $0.25 \mu \mathrm{m}$ film (Agilent Technologies Inc.) was used for the separation. The ICS samples in a $20 \mathrm{~mL}$ headspace vial were heated at an equilibrium temperature of $130^{\circ} \mathrm{C}$ for $40 \mathrm{~min}$, and the gas phase were injected into the GC-MS for analysis. The injection time was $1.0 \mathrm{~min}$. A low shaker mode of the headspace vial was applied during sample heating.

GC parameters were as follows: The carrier gas and make-up gas were high pure helium and nitrogen, respectively. The carrier gas (helium) was set at a flow rate of $1.0 \mathrm{~mL} \cdot \mathrm{min}^{-1}$. The inlet temperature was $200{ }^{\circ} \mathrm{C}$ with a split ratio of $10: 1$ and the pressure was $11.6 \mathrm{psi}$. The column oven temperature was initially set at $60^{\circ} \mathrm{C}$ for $5 \mathrm{~min}$, and then ramped to $200{ }^{\circ} \mathrm{C}$ at $5{ }^{\circ} \mathrm{C} \cdot \mathrm{min}^{-1}$ for $5 \mathrm{~min}$, and after that, it was warmed up to $300^{\circ} \mathrm{C}$ at $10^{\circ} \mathrm{C} \cdot \mathrm{min}^{-1}$.

MS parameters were as follows: Data were acquired in the electron impact (EI) mode, using the full scan mode from $\mathrm{m} / \mathrm{z} 30$ to 600 at $1562 \mathrm{amu} / \mathrm{s}$. The ion source temperature and quadrupole temperature were 230 and $150{ }^{\circ} \mathrm{C}$, respectively. The identification of volatile compounds was based on a comparison of their GC retention time and mass spectra with the retention index of n-alkane saturated alkanes and the reference spectra from the US National Institute of Standards and Technology (NIST, 2014). The values were the mean of three replicates of each sample. Data were analyzed by using Agilent MassHunter Analysis.

\subsection{Preparation of ICS Samples for SHS-GC-MS Analysis}

About $1 \mathrm{~g}$ of ICS powder was accurately weighed and added into a $20 \mathrm{~mL}$ headspace vial by adding $5 \mathrm{~mL}$ NADES, mixed and sealed for SHS-GC-MS analysis. For analysis work, all the NADESs were added to $15 \%$ water in a weight ratio, respectively, except for the optimization experiments of the water content in NADESs. The solid-liquid ratio in the headspace vial was 1:5 (g:mL) for all the experiments except the optimization experiments of the solid-liquid ratio. The other experiment conditions were the same as that listed in Section 2.4. Each sample was determined in triplicate.

\subsection{Determination of Retention Index}

A $500 \mu \mathrm{L}$ pipette of $\mathrm{C}_{7}-\mathrm{C}_{40}$ n-alkane saturated alkane mixture was placed into a $10 \mathrm{~mL}$ volumetric flask and diluted to the volume with n-hexane to make a concentration of $50 \mu \mathrm{L} / \mathrm{mL}$ solution. Then, $3 \mathrm{~mL}$ of alkane solution was transferred to a $20 \mathrm{~mL}$ headspace vial for SHS-GC-MS analysis. The SHS-GC-MS conditions were the same as that in Section 2.4. The sample was analyzed in triplicate.

The formula used for calculating the retention index was as follows:

$$
R I=100 Z+100 \frac{T R(x)-T R(z)}{T R(z+1)-T R(z)},
$$

where $T R(x), T R(z)$, and $T R(z+1)$ represent the retention temperature of the component, the n-alkane with carbon number at $z$ and $z+1$, respectively, and $T R(z)<T R(x)<T R(z+1)$. The retention temperature was obtained according to the temperature programming. 


\section{Results and Discussions}

\subsection{Optimization of SHS Parameters}

The equilibrium time and temperature were the key operating parameters affecting the SHS efficiency. The equilibrium temperature often depends on the dilution matrix used in SHS. To obtain the optimized equilibrium temperature, different temperatures of $100,110,120,130$, and $140{ }^{\circ} \mathrm{C}$ were carried out in NADES-2 containing 15\% water for SHS-GC-MS analysis. As shown in Figure S1a, with the increase of the temperature, the number of peaks detected in the ICS samples increased. When the equilibrium temperature was raised to $130{ }^{\circ} \mathrm{C}$, greater peak numbers with a better response were observed. Similar results were obtained at $140{ }^{\circ} \mathrm{C}$, but the peak numbers were somewhat decreased. Although the high temperature was beneficial for increasing the peak response of the volatile compounds, the excessive high temperatures could result in the degradation of thermally unstable compounds. As a result, $130^{\circ} \mathrm{C}$ was selected as the preferred equilibrium temperature.

On the other hand, the appropriate equilibrium time also played an important role for achieving the gas-liquid balance. Similar to the above operation, the equilibrium time at 20,30, 40, 50, and 60 min were evaluated in NADES-2 containing 15\% water with the other experiment conditions the same as that listed in Section 2.5. As shown in Figure S1b, the number of peaks detected at 40 min were more than those at other equilibrium times and $40 \mathrm{~min}$ was chosen to be the preferred equilibrium time.

\subsection{Selection of NADESs for SHS-GC-MS Analysis}

Six NADESs were prepared, including choline chloride-citric acid, in a 1:1 molar ratio (NADES-1), choline chloride-glucose in a 1:1 molar ratio (NADES-2), choline chloride-1, 4-butanediol in a 1:2 molar ratio (NADES-3), choline chloride-levulinic acid in a 1:2 molar ratio (NADES-4), choline chloride-fructose in a 1:1 molar ratio (NADES-5), and choline chloride-maltose (NADES-6). Transparent solutions were obtained and no precipitation were observed during storage at room temperature. All these NADESs were added to $15 \%$ water in a weight ratio before application for further analysis.

To verify the feasibility of NADESs as an SHS dilution matrix, the comparison of the total ion chromatograms of ICS samples between the ICS essential oil, which was prepared by steam distillation, and the ICS powder in NADES-2 containing 15\% water were preliminarily performed as shown in Figure S2. These two samples were detected in the same experiment conditions except different injection methods were used. The ICS essential oil was detected by the direct GC-MS method while the ICS powder was put into a headspace vial with the addition of NADES-2 containing $15 \%$ water as the dilution matrix and determined by the SHS-GC-MS method. The results showed that the relatively higher responses with more components were detected from the latter than the former, especially the low boiling point components, which were probably lost by the extraction process of the essential oil. It was reported that NADESs can be used to dissolve cellulose and lignin which facilitate the release of compounds from plant tissues [33,34]. As a dilution matrix in SHS, the NADESs used in this work also exhibited good dissolving or extracting properties for the volatile components in ICS leaves.

However, for the six NADESs prepared in this study, they exhibited different analysis characteristics as shown in Figure 1 . It was found that three sesquiterpenes, including $\beta$-elemene, $\beta$-caryophyllene, and $\alpha$-humulene, were the main volatile components in the ICS leaves. The peak areas of these three main compounds and the number of peaks detected were used as one of the key parameters for further analysis of the optimal conditions. A few components were detected in both NADES-3 and NADES-4. More components were observed in NADES-1 and 2 than in NADES-5 and 6. Although a little bit more components were observed in NADES-1, the higher peak areas of the three main compounds were obtained in NADES-2, and NADES-2 was selected as the optimized dilution matrix for further investigation. 

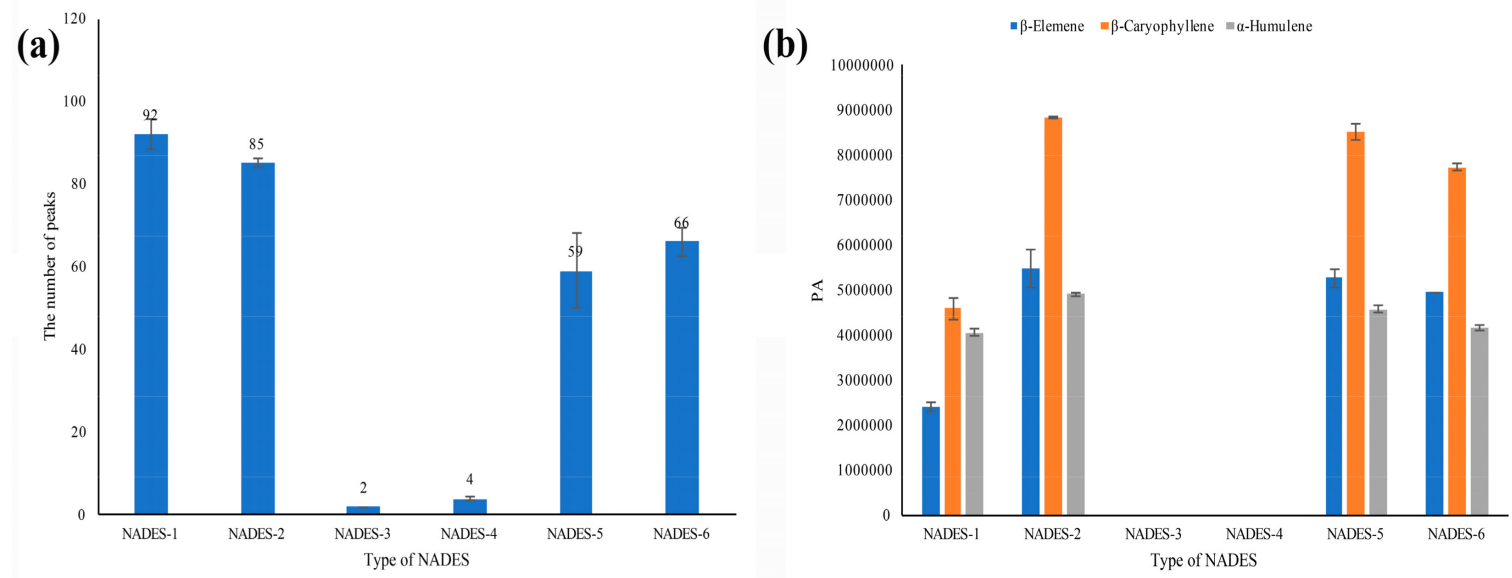

Figure 1. Comparison of peak responses of Ipomoea cairica (L.) Sweet (ICS) samples in different natural deep eutectic solvents (NADESs) containing 15\% water: (a) the number of peaks; (b) the peak areas of three main components.

\subsection{Effects of the Solid-Liquid Ratio and Water Content of NADESs on SHS Efficiency}

The peak responses of compounds or the headspace efficiency were greatly affected by the concentration ratio between the analyte in the dilution matrix and the gas phase in the headspace vial [35]. It was reasonable that a large amount of dilution matrix would decrease the equilibrium concentration of the analyte in the gas phase of the headspace vial and hence decrease the headspace efficiency. To explore the suitable amount of NADESs used in headspace vials, different solid-liquid ratios (ratios of the ICS powder weight and the NADES volume) ranging from 1:5 to 1:50 were investigated. Since the peak numbers were similar, the peak areas of the three main components were used as the key parameters for comparison and the results are shown in Figure 2a. With an increasing of the solid-liquid ratios, the peak areas of three main components decreased. As a result, the solid-liquid ratio at 1:5 was preferred.

(a)

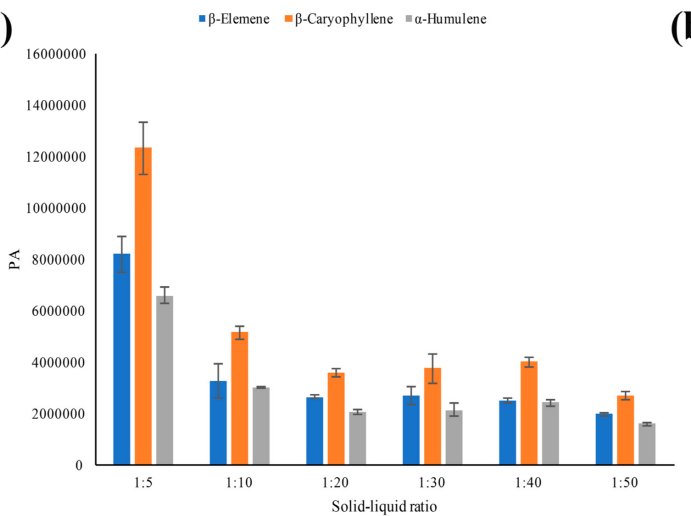

(b)

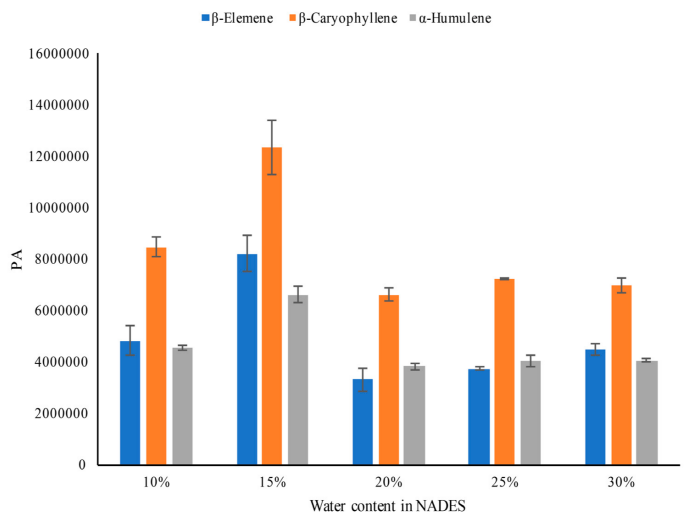

Figure 2. The peak areas of the three main components in ICS leaves: (a) in different solid-liquid ratios; (b) NADES-2 containing different amount of water.

Although NADES has been demonstrated to have many superiorities and has a wide application as a new type of solvent, its high viscosity makes its application somewhat inconvenient $[36,37]$. The viscosity of NADESs could be largely decreased by adding water. In this study, the NADES-2 with the addition of $10 \%, 15 \%, 20 \%, 25 \%$, and $30 \%$ (wt $\%$ ) water were evaluated for the SHS efficiency. Figure $2 \mathrm{~b}$ showed that the peak areas of the three main components increased slightly by adding $10 \%$ to $15 \%$ of water. However, when the amount of water was over $15 \%$, the peak areas decreased. It may 
be attributed to the fact that the hydrogen bonding network in NADES is weakened by adding a large amount of water [38]. As a result, the NADES- 2 with $15 \%$ water content was the better choice.

\subsection{Volatile Components' Characterization by SHS-GC-MS}

The total ion chromatography (TIC) under the optimized conditions is shown in Figure 3. A total of 77 volatile compounds in the ICS leaves were tentatively illustrated by matching the mass spectra with the NIST14 Mass Spectral Library and the NIST MS Search 2.2 for the reference retention index. The mass spectra matching was affected by many factors, such as the reference spectral library, spectral similarity measurement, and weight factor [39,40]. In addition, mass spectral matching cannot distinguish isomers from each other. For natural products, isomers were the common phenomena and showed very similar mass spectra. To differentiate these isomers, the retention index provides a better choice due to the different retention index of the isomers [41,42]. In this work, the retention index of the components was calculated and used for the identification of compounds in ICS leaves as listed in Table 1.

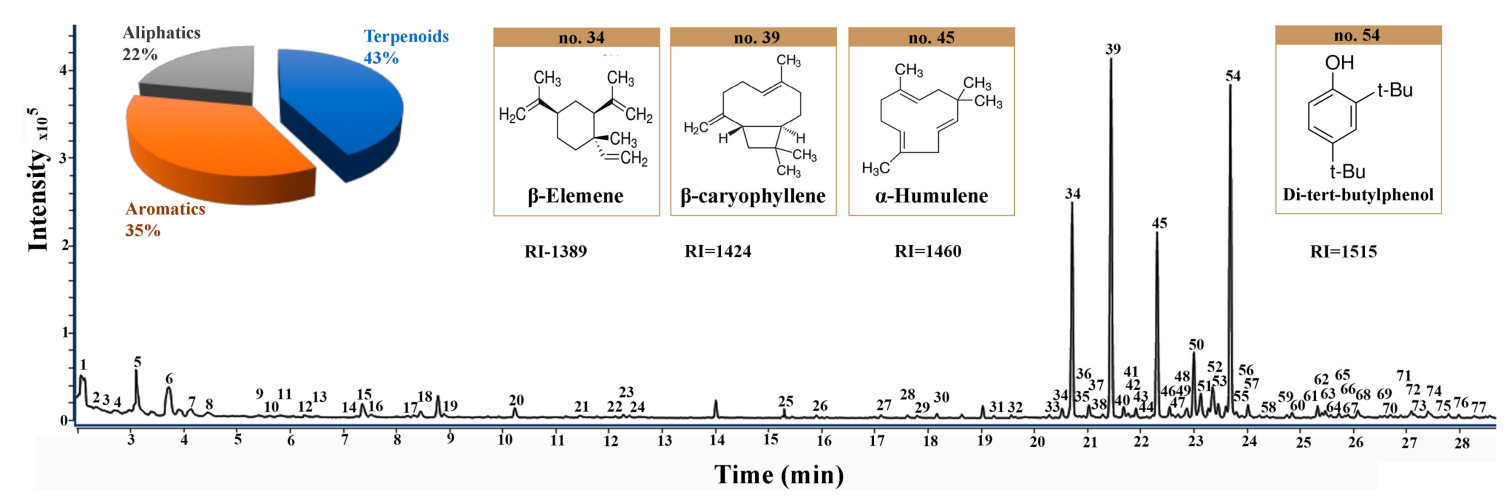

Figure 3. The total ion chromatography (TIC) of ICS leaves in NADES-2 containing $15 \%$ water and the molecular structures of main volatile constituents (No. 34, 39, 45, and 54). 
Table 1. Compounds tentatively illustrated of Ipomoea cairica Sweet leaves detected by SHS-GC-MS.

\begin{tabular}{|c|c|c|c|c|c|c|c|}
\hline No. & Components & RT & Formula & CAS & Score & RI & Contents * $(\%)$ \\
\hline 1 & 5-Methyl-5-hexen-2-ol & 2.07 & $\mathrm{C}_{7} \mathrm{H}_{14} \mathrm{O}$ & $50551-88-7$ & 70.73 & 692 & 3.65 \\
\hline 2 & 2-Ethyl-furan & 2.14 & $\mathrm{C}_{6} \mathrm{H}_{8} \mathrm{O}$ & $3208-16-0$ & 77.37 & 708 & 1.41 \\
\hline 3 & 1-(Methylencyclopropyl)-ethanol & 2.36 & $\mathrm{C}_{6} \mathrm{H}_{10} \mathrm{O}$ & & 70.89 & 725 & 0.14 \\
\hline 4 & 4-Penten-1-ol & 2.69 & $\mathrm{C}_{5} \mathrm{H}_{10} \mathrm{O}$ & $821-09-0$ & 65.28 & 766 & 0.43 \\
\hline 5 & 2, 4-Dimethyl-3-pentanol & 3.10 & $\mathrm{C}_{7} \mathrm{H}_{16} \mathrm{O}$ & $600-36-2$ & 80.18 & 803 & 3.75 \\
\hline 6 & 3-Furaldehyde & 3.72 & $\mathrm{C}_{5} \mathrm{H}_{4} \mathrm{O} 2$ & $498-60-2$ & 90.06 & 829 & 4.73 \\
\hline 7 & (E)-2-hexenal & 4.15 & $\mathrm{C}_{6} \mathrm{H}_{10} \mathrm{O}$ & $6728-26-3$ & 80.70 & 849 & 1.07 \\
\hline 8 & 4-Methyl-2-penten-1-ol & 4.46 & $\mathrm{C}_{6} \mathrm{H}_{12} \mathrm{O}$ & $5362-55-0$ & 67.13 & 863 & 0.59 \\
\hline 9 & Heptanal & 5.42 & $\mathrm{C}_{7} \mathrm{H}_{14} \mathrm{O}$ & $111-71-7$ & 67.55 & 904 & 0.27 \\
\hline 10 & (+/-)-2-Amino-1-propanol & 5.61 & $\mathrm{C}_{3} \mathrm{H}_{9} \mathrm{NO}$ & 2749-11-3 & 72.19 & 910 & 0.13 \\
\hline 11 & 1-(2-Furanyl)-ethanone, & 5.83 & $\mathrm{C}_{6} \mathrm{H}_{6} \mathrm{O}_{2}$ & $1192-62-7$ & 60.92 & 916 & 0.30 \\
\hline 12 & Butyrolactone & 6.26 & $\mathrm{C}_{4} \mathrm{H}_{6} \mathrm{O}_{2}$ & $96-48-0$ & 63.77 & 923 & 0.21 \\
\hline 13 & (1R)-2, 6, 6-Trimethylbicyclo [3.1.1] hept-2-ene & 6.50 & $\mathrm{C}_{10} \mathrm{H}_{16}$ & $7785-70-8$ & 54.28 & 936 & 0.14 \\
\hline 14 & 1-Methyl-3-cyclohexen-1-ol & 7.27 & $\mathrm{C}_{7} \mathrm{H}_{12} \mathrm{O}$ & $33061-16-4$ & 53.39 & 959 & 0.12 \\
\hline 15 & Benzaldehyde & 7.36 & $\mathrm{C}_{7} \mathrm{H}_{8} \mathrm{O}$ & $100-52-7$ & 87.31 & 962 & 1.52 \\
\hline 16 & 1-Methyl-pyrazole-4-carboxaldehyde & 7.53 & $\mathrm{C}_{5} \mathrm{H}_{6} \mathrm{~N}_{2} \mathrm{O}$ & 25016-11-9 & 73.89 & 966 & 0.41 \\
\hline 17 & 2-Methyl-1-hepten-6-one & 8.34 & $\mathrm{C}_{8} \mathrm{H}_{14} \mathrm{O}$ & $10408-15-8$ & 69.68 & 991 & 0.19 \\
\hline 18 & 2-Pentyl-furan & 8.46 & $\mathrm{C}_{9} \mathrm{H}_{14} \mathrm{O}$ & $3777-69-3$ & 77.14 & 994 & 0.57 \\
\hline 19 & 1-Methyl-1H-pyrrole-2-carboxaldehyde & 8.90 & $\mathrm{C}_{6} \mathrm{H}_{7} \mathrm{NO}$ & 1192-58-1 & 67.63 & 1004 & 0.31 \\
\hline 20 & Benzeneacetaldehyde & 10.22 & $\mathrm{C}_{8} \mathrm{H}_{8} \mathrm{O}$ & $122-78-1$ & 85.65 & 1023 & 0.81 \\
\hline 21 & 2, 5-Furandicarboxaldehyde & 11.44 & $\mathrm{C}_{6} \mathrm{H}_{4} \mathrm{O}_{3}$ & $823-82-5$ & 61.79 & 1042 & 0.19 \\
\hline 22 & Nonanal & 12.27 & $\mathrm{C}_{9} \mathrm{H}_{18} \mathrm{O}$ & $124-19-6$ & 74.41 & 1107 & 0.20 \\
\hline 23 & Levomenthol & 12.38 & $\mathrm{C}_{10} \mathrm{H}_{20} \mathrm{O}$ & $2216-51-5$ & 65.21 & 1110 & 0.16 \\
\hline 24 & Phenylethyl alcohol & 12.57 & $\mathrm{C}_{8} \mathrm{H}_{10} \mathrm{O}$ & $60-12-8$ & 73.38 & 1116 & 0.17 \\
\hline 25 & 2, 6, 6-Trimethyl-1, 3-cyclohexadiene-1-carboxaldehyde & 15.27 & $\mathrm{C}_{10} \mathrm{H}_{14} \mathrm{O}$ & $116-26-7$ & 61.78 & 1202 & 0.10 \\
\hline 26 & 2, 6, 6-Trimethyl-1-cyclohexene-1-carboxaldehyde & 15.90 & $\mathrm{C}_{10} \mathrm{H}_{16} \mathrm{O}$ & $432-25-7$ & 64.44 & 1204 & 0.16 \\
\hline 27 & 4-(2, 6, 6-Trimethyl-1, 3-cyclohexadien-1-yl)-2-butanone & 17.11 & $\mathrm{C}_{13} \mathrm{H}_{20} \mathrm{O}$ & 20483-36-7 & 66.03 & 1266 & 0.20 \\
\hline 28 & $(1 \mathrm{R}, 2 \mathrm{R}, 5 \mathrm{R}, \mathrm{E})$-7-Ethylidene-1, 2, 8, 8-tetramethylbicyclo [3.3.1] octane & 17.61 & $\mathrm{C}_{14} \mathrm{H}_{14}$ & 193695-14-6 & 54.09 & 1283 & 0.17 \\
\hline 29 & Tetrahydro-6-propyl-2H-pyran-2-one & 17.79 & $\mathrm{C}_{8} \mathrm{H}_{14} \mathrm{O}_{2}$ & $542-28-9$ & 69.71 & 1289 & 0.19 \\
\hline 30 & $2,6,10,10$-Tetramethyl-1-oxaspiro [4.5] dec-6-ene & 18.17 & $\mathrm{C}_{13} \mathrm{H}_{22} \mathrm{O}$ & $36431-72-8$ & 80.79 & 1302 & 0.25 \\
\hline 31 & (3R-trans)-4-Ethenyl-4-methyl-3-(1-methylethenyl)-1-(1-methylethyl)-cyclohexene & 19.24 & $\mathrm{C}_{15} \mathrm{H}_{24}$ & 20307-84-0 & 73.27 & 1342 & 0.14 \\
\hline 32 & trans-Calamenene & 19.57 & $\mathrm{C}_{15} \mathrm{H}_{22}$ & $73209-42-4$ & 74.69 & 1355 & 0.14 \\
\hline 33 & $\alpha$-Cubebene & 20.28 & $\mathrm{C}_{5} \mathrm{H}_{24}$ & $17699-14-8$ & 81.24 & 1381 & 0.17 \\
\hline 34 & $\beta$-Elemene & 20.52 & $\mathrm{C}_{15} \mathrm{H}_{24}$ & $515-13-9$ & 97.06 & 1389 & 0.63 \\
\hline 35 & 2, 4, 6-Trimethyl-decane & 20.85 & $\mathrm{C}_{12} \mathrm{H}_{26}$ & 2801-84-5 & 51.23 & 1402 & 0.11 \\
\hline 36 & $\delta$-Selinene & 20.92 & $\mathrm{C}_{15} \mathrm{H}_{24}$ & $28624-23-9$ & 71.98 & 1405 & 0.11 \\
\hline 37 & 4-(Dimethylamine)-benzaldehyde & 21.02 & $\mathrm{C}_{9} \mathrm{H}_{11} \mathrm{NO}$ & $100-10-7$ & 90.17 & 1409 & 0.90 \\
\hline
\end{tabular}


Table 1. Cont.

\begin{tabular}{|c|c|c|c|c|c|c|c|}
\hline No. & Components & RT & Formula & CAS & Score & RI & Contents * $(\%)$ \\
\hline 38 & (E)-1-(2, 3, 6-trimethylphenyl) buta-1, 3-diene (TPB,1) & 21.29 & $\mathrm{C}_{13} \mathrm{H}_{16}$ & 1000357-25-7 & 58.90 & 1419 & 0.23 \\
\hline 39 & $\beta$-Caryophyllene & 21.44 & $\mathrm{C}_{15} \mathrm{H}_{24}$ & $87-44-5$ & 98.21 & 1424 & 22.68 \\
\hline 40 & (+)-epi-Bicyclosesquiphellandrene & 21.67 & $\mathrm{C}_{15} \mathrm{H}_{24}$ & $54274-73-6$ & 93.89 & 1435 & 0.75 \\
\hline 41 & $\begin{array}{l}\text { [1aR-(1a } \alpha, 7 \mathrm{a} \alpha, 7 \mathrm{~b} \alpha)]-1 \mathrm{a}, 2,3,5,6,7,7 \mathrm{a}, 7 \mathrm{~b}-O c t a h y d r o-1,1,7,7 \mathrm{a} \text {-tetramethyl-1H-cyclopropa } \\
\text { [a] naphthalene }\end{array}$ & 21.76 & $\mathrm{C}_{15} \mathrm{H}_{24}$ & $17334-55-3$ & 82.99 & 1439 & 0.32 \\
\hline 42 & (1S-cis)-1, 2, 3, 5, 6, 8a-Hexaahydro-4, 7-dimethyl-1-(1-methylethyl)-naphthalene & 21.84 & $\mathrm{C}_{15} \mathrm{H}_{24}$ & 483-76-1 & 75.42 & 1442 & 0.12 \\
\hline 43 & $\alpha$-Guaiene & 21.91 & $\mathrm{C}_{15} \mathrm{H}_{24}$ & $3691-12-1$ & 90.65 & 1444 & 0.58 \\
\hline 44 & cis-Calamenene & 22.23 & $\mathrm{C}_{15} \mathrm{H}_{22}$ & $72937-55-4$ & 69.79 & 1457 & 0.18 \\
\hline 45 & $\alpha$-Humulene & 22.31 & $\mathrm{C}_{15} \mathrm{H}_{24}$ & $6753-98-6$ & 97.41 & 1460 & 11.23 \\
\hline 46 & Bicyclosesquiphellandrene & 22.54 & $\mathrm{C}_{15} \mathrm{H}_{24}$ & 54324-03-7 & 91.10 & 1469 & 0.61 \\
\hline 47 & 2, 6-Bis (1, 1-dimethylethyl)-2, 5-cyclohexadiene-1, 4-dione & 22.61 & $\mathrm{C}_{14} \mathrm{H}_{20} \mathrm{O}_{2}$ & $719-22-2$ & 91.04 & 1472 & 0.11 \\
\hline 48 & cis-Muurola-4(15), 5-diene & 22.70 & $\mathrm{C}_{15} \mathrm{H}_{24}$ & 157477-72-0 & 68.22 & 1476 & 0.14 \\
\hline 49 & $(1 \alpha, 4 a \beta, 8 \mathrm{a} \alpha)-(+/-)-1,2,4 a, 5,8,8 \mathrm{a}-H e x a h y d r o-4,7-1-(1-m e t h y l e t h y l)-n a p h t h a l e n e$ & 22.86 & $\mathrm{C}_{15} \mathrm{H}_{24}$ & $5951-61-1$ & 89.26 & 1482 & 0.75 \\
\hline 50 & $\beta$-Guaiene & 23.00 & $\mathrm{C}_{15} \mathrm{H}_{24}$ & 88-84-6 & 93.97 & 1487 & 4.09 \\
\hline 51 & [4aR-(4a $\alpha, 7 \alpha, 8 \mathrm{a} \beta)]$-Decahydro-4a-methyl-1-methylene-7-(1-methylethenyl)-naphthalene & 23.13 & $\mathrm{C}_{15} \mathrm{H}_{24}$ & $17066-67-0$ & 87.43 & 1493 & 2.13 \\
\hline 52 & 2-Isopropenyl-4a, 8-dimethyl-1, 2, 3, 4, 4a, 5, 6, 8a-octahydronaphthalene & 23.35 & $\mathrm{C}_{15} \mathrm{H}_{24}$ & $1000193-57-0$ & 90.13 & 1501 & 2.78 \\
\hline 53 & [1S-( $1 \alpha, 7 \alpha, 8 \mathrm{a} \beta)]-1,2,3,5,6,7,8,8 \mathrm{a}$-octahydro-1,4-dimethyl-7-(1-methylethenyl)-azulene & 23.60 & $\mathrm{C}_{15} \mathrm{H}_{24}$ & $3691-11-0$ & 89.20 & 1512 & 0.70 \\
\hline 54 & Di-tert-butylphenol & 23.69 & $\mathrm{C}_{14} \mathrm{H}_{22} \mathrm{O}$ & 96-76-4 & 93.23 & 1515 & 20.11 \\
\hline 55 & 1, 2, 3, 4, 4a, 5, 6, 8a-Octahydro-7-methyl-4-methylene-naphthalene & 23.80 & $\mathrm{C}_{15} \mathrm{H}_{24}$ & $39029-41-9$ & 76.36 & 1520 & 0.37 \\
\hline 56 & Selina-3, 7(11)-diene & 23.90 & $\mathrm{C}_{15} \mathrm{H}_{24}$ & 6813-21-4 & 54.29 & 1525 & 0.12 \\
\hline 57 & (1S-cis)-1, 2, 3, 5, 6, 8a-Hexahydro-4, 7-dimethyl-1-(1-methylethyl)-naphthalene & 24.02 & $\mathrm{C}_{15} \mathrm{H}_{24}$ & 483-76-1 & 90.16 & 1530 & 0.90 \\
\hline 58 & Epizonarene & 24.37 & $\mathrm{C}_{15} \mathrm{H}_{24}$ & $41702-63-0$ & 63.48 & 1544 & 0.16 \\
\hline 59 & Caryophyllene oxide & 24.74 & $\mathrm{C}_{15} \mathrm{H}_{24} \mathrm{O}$ & $1139-30-6$ & 59.71 & 1560 & 0.18 \\
\hline 60 & Patchoulene & 24.84 & $\mathrm{C}_{15} \mathrm{H}_{26}$ & 25491-20-7 & 85.19 & 1565 & 0.34 \\
\hline 61 & Dehydro-aromadendrene & 25.32 & $\mathrm{C}_{15} \mathrm{H}_{22}$ & & 85.63 & 1585 & 0.78 \\
\hline 62 & $\beta$-Vatirenene & 25.41 & $\mathrm{C}_{15} \mathrm{H}_{22}$ & $27840-40-0$ & 72.71 & 1588 & 0.35 \\
\hline 63 & Aristol-1(10)-en-9-ol & 25.47 & $\mathrm{C}_{15} \mathrm{H}_{24} \mathrm{O}$ & $1372763-27-3$ & 81.55 & 1591 & 0.54 \\
\hline 64 & (8R, 8aS)-8, 8a-Dimethyl-2-(propan-2-ylidene)-1, 2, 3, 7, 8, 8a-hexahydronaphthalene & 25.57 & $\mathrm{C}_{15} \mathrm{H}_{22}$ & $27840-40-0$ & 69.23 & 1595 & 0.15 \\
\hline 65 & Salvial-4(14)-en-1-one & 25.73 & $\mathrm{C}_{15} \mathrm{H}_{24} \mathrm{O}$ & $73809-82-2$ & 66.55 & 1602 & 0.31 \\
\hline 66 & 1,3-Bis-(2-cyclopropyl,2-methylcyclopropyl)-but-2-en-1-one & 25.85 & $\mathrm{C}_{18} \mathrm{H}_{26} \mathrm{O}$ & & 72.68 & 1607 & 0.11 \\
\hline 67 & $\begin{array}{l}{[3 \mathrm{R}-(3 \alpha, 3 \mathrm{a} \beta, 7 \beta, 8 \mathrm{a} \alpha)]-2,3,4,7,8,8 \mathrm{a}-H e x a h y d r o-3,6,8,8 \text {-tetramethyl-1H-3a, }} \\
\text { 7-methanoazulene }\end{array}$ & 25.90 & $\mathrm{C}_{15} \mathrm{H}_{24}$ & $469-61-4$ & 74.34 & 1610 & 0.19 \\
\hline 68 & $(+)$-Epi-, $\beta$-santalyl acetate & 26.09 & $\mathrm{C}_{17} \mathrm{H}_{26} \mathrm{O}_{2}$ & 41414-75-9 & 75.95 & 1617 & 0.64 \\
\hline 69 & (1S, 7S, 8aR)-1, 8a-Dimethyl-7-(prop-1-en-2-yl)-1, 2, 3, 7, 8, 8a-hexahydronaphthalene & 26.60 & $\mathrm{C}_{15} \mathrm{H}_{22}$ & 190327-38-9 & 61.30 & 1640 & 0.11 \\
\hline
\end{tabular}


Table 1. Cont.

\begin{tabular}{|c|c|c|c|c|c|c|c|}
\hline No. & Components & RT & Formula & CAS & Score & RI & Contents * $(\%)$ \\
\hline 70 & 4a, 5-Dimethyl-3-(prop-1-en-2-yl)-1, 2, 3, 4, 4a, 5, 6, 7-octahydronaphthalen-1-ol & 26.69 & $\mathrm{C}_{15} \mathrm{H}_{24} \mathrm{O}$ & $61847-19-6$ & 67.23 & 1645 & 0.19 \\
\hline 71 & 1-Isopropyl-4, 7-dimethyl-1, 2, 3, 4, 5, 6-hexahydronaphthalene & 26.89 & $\mathrm{C}_{15} \mathrm{H}_{24}$ & $16729-00-3$ & 59.31 & 1649 & 0.12 \\
\hline 72 & (4aR-trans)-Decahydro-4a-methyl-1-methylene-7-(1-methylethylidene)-naphthalene & 27.09 & $\mathrm{C}_{15} \mathrm{H}_{24}$ & $515-17-3$ & 80.30 & 1662 & 0.62 \\
\hline 73 & trans-Valerenyl acetate & 27.14 & $\mathrm{C}_{17} \mathrm{H}_{26} \mathrm{O}_{2}$ & 101527-74-6 & 72.98 & 1665 & 0.21 \\
\hline 74 & $\begin{array}{l}\text { (E)-2-((8R, 8aS)-8, 8a-Dimethyl-3, 4, 6, 7, 8, 8a-hexahydronaphthalen-2 (1H)-ylidene) } \\
\text { propyl formate }\end{array}$ & 27.41 & $\mathrm{C}_{16} \mathrm{H}_{24} \mathrm{O}_{2}$ & $352457-47-7$ & 54.29 & 1679 & 0.72 \\
\hline 75 & cis- $\alpha$-Copaene-8-ol & 27.79 & $\mathrm{C}_{15} \mathrm{H}_{24} \mathrm{O}$ & $58569-25-8$ & 55.35 & 1694 & 0.29 \\
\hline 76 & Heptadecane & 27.98 & $\mathrm{C}_{17} \mathrm{H}_{36}$ & 629-78-7 & 68.57 & 1702 & 0.19 \\
\hline 77 & (E)-1, 3, 3-trimethyl-2-(3-methyl-2-methylene-3-butenylidene)-cyclohexanol & 28.27 & $\mathrm{C}_{15} \mathrm{H}_{24} \mathrm{O}$ & $69296-93-1$ & 50.18 & 1716 & 0.14 \\
\hline
\end{tabular}

* The relative peak area normalization content obtained from the TIC chromatogram. 


\subsubsection{Identification of Terpenoids}

Terpenoids were the main volatile components in the ICS leaves. Compounds 23, 31, 32, 33, $34,36,39,40,43,44,45,46,49,50,53,56,58,59,60,61,62,63,65,67$, and 75 were identified as terpenoids. Among them, the $\beta$-caryophyllene (compound 39), $\beta$-elemene (compound 34), and $\alpha$-humulene (compound 45) were observed to be the main components. Most terpenoids have abundant pharmacological activities. They are used for analgesic and itching, and have antiseptic and bactericidal effects. $\beta$-Elemene is useful for killing tumor cells and conventional doses have no effect on normal cells [43]. $\beta$-Caryophyllene $[44,45]$ is widely used as a spice in cosmetics and food additives. Pharmacological studies showed that $\beta$-caryophyllene has local anesthetic, anti-inflammatory, insect repellent, anti-anxiety and anti-depression effects. $\beta$-Caryophyllene is also used in antitussive and expectorant drugs. Compound $\mathbf{3 4}$ was used as an example to elucidate the identification work of these terpenoids. The mass spectrum of compound 34 showed the molecular ion at $m / z 204.2$ and the fragment ions at $m / z$ 189.2, 175.1, 161.1, 147.1, 133.1, 121.1, 107.1, 93.1, 81.1, 68.1, 55.1, 41.1, and 32.0, respectively. The mass spectral matching result showed that $\beta$-elemene had a high matching score of 97. The retention index of compound 34 was 1389 , which was similar to the reference retention index 1398 of $\beta$-elemene. As a result, compound 34 was identified as $\beta$-elemene.

\subsubsection{Identification of Aromatics}

Compounds 14, 15, 19, 20, 24, 37, 41, 42, 48, 51, 52, 54, 55, 57, 64, 69, 70, 71, 72, 74, and 76 were identified as aromatic compounds. The high content of di-tert-butylphenol (compound 54) was found in the ICS leaves, which is reported to have antifungal and antioxidant activities [46]. Compound 54 was used as an example to elucidate the identification work of these aromatics. The mass spectrum of compound $\mathbf{5 4}$ showed that the molecular ion at $m / z 206.2$ and the fragment ions were $\mathrm{m} / \mathrm{z} 191.1,175.1,163.1,147.1,128.1,107.0,91.0,74.0,66.0,57.1,51.0,40.0$, and 32.0, respectively. The mass spectral matching result showed that 2,4-di-tert-butylphenol had a high matching score of 92 . The retention index of compound $\mathbf{5 4}$ was 1515, which was the similar to the reference retention index 1519. The compound 54 was identified as 2,4-di-tert-butylphenol.

\subsubsection{Identification of Aliphatics}

Compounds 1-13, 17-18, 21, 22, 25-30, 35, 38, 47, 66, 68, 73, and 77 were identified as aliphatic compounds. The contents of aliphatic compounds were relatively low. Compound 6 was used as an example to elucidate the identification work of these aromatics. The mass spectrum of compound 6 showed that the molecular ion at $m / z 96.0$ and the fragment ions were $m / z$ 87.0, 73.0, 67.0, 58.1, 51.0, 44.0, 39.0, and 32.0, respectively. The mass spectral matching result showed that 3-furaldehyde had a high matching score of 94 . The retention index of compound 6 was 829 , which was similar to the reference retention index 832 of 3-furaldehyde. As a result, the compound 6 was identified as 3-furaldehyde.

\section{Conclusions}

In conclusion, the green solvent NADESs as both an extraction and dilution matrix were successfully applied to the volatile components analysis in ICS leaves by the SHS-GC-MS method. Different kinds of NADESs exhibited different SHS efficiencies for the various volatile components. For the volatile components in ICS leaves, the NADES composed of choline chloride and glucose with a 1:1 molar ratio containing $15 \%$ water showed the preferred results. With the optimized analysis conditions, a total of 77 volatiles in ICS leaves were tentatively identified and assigned by mass spectral matching with the standard mass spectral library and the retention index-assisted qualitative method. The main contents in ICS leaves were $\beta$-elemene, $\beta$-caryophyllene, $\alpha$-humulene, and 2,4-di-tert-butylphenol. Based on the results obtained in this study, NADESs were demonstrated to be the efficient green extraction and dilution matrix in the SHS-GC-MS method and could be directly used for volatile components analysis of plant materials without extra extraction work. 
Supplementary Materials: The following are available online at http://www.mdpi.com/2304-8158/8/6/205/s1, Figure S1: Comparison of the peak numbers obtained from different conditions: (a) different equilibrium temperatures; (b) different equilibrium time, Figure S2: The comparison of the total ion chromatograms of ICS samples: (a) the ICS essential oil; (b) the ICS powder in NADES-2 containing $15 \%$ water.

Author Contributions: Formal analysis, X.L. and W.Z.; Investigation, W.Z.; Methodology, X.L.; Resources, X.L.; Writing—original draft, W.Z.; Writing—review and editing, X.L.

Funding: This research received no external funding.

Conflicts of Interest: The authors declare no conflict of interest.

\section{References}

1. Maffei, M.E.; Gertsch, J.; Appendino, G. Plant Volatiles: Production, Function and Pharmacology. Nat. Prod. Rep. 2011, 28, 1359-1380. [CrossRef] [PubMed]

2. Giacometti, J.; Kovačević, D.B.; Putnik, P.; Gabrić, D.; Bilušić, T.; Krešić, G.; Stulić, V.; Barba, F.J.; Chemat, F.; Barbosa-Cánovas, G.; et al. Extraction of bioactive compounds and essential oils from mediterranean herbs by conventional and green innovative techniques: A review. Food Res. Int. 2018, 113, 245-262. [CrossRef] [PubMed]

3. Valencia-Sullca, C.; Vargas, M.; Atarés, L.; Chiralt, A. Thermoplastic cassava starch-chitosan bilayer films containing essential oils. Food Hydrocolloid. 2018, 75, 107-115. [CrossRef]

4. Amorati, R.; Foti, M.C.; Valgimigli, L. Antioxidant Activity of Essential Oils. J. Agric. Food Chem. 2013, 61, 10835-10847. [CrossRef] [PubMed]

5. Tohidi, B.; Rahimmalek, M.; Arzani, A. Essential oil composition, total phenolic, flavonoid contents, and antioxidant activity of Thymus species collected from different regions of Iran. Food Chem. 2017, 220, $153-161$. [CrossRef] [PubMed]

6. Filly, A.; Fernandez, X.; Minuti, M.; Visinoni, F.; Cravotto, G.; Chemat, F. Solvent-free microwave extraction of essential oil from aromatic herbs: From laboratory to pilot and industrial scale. Food Chem. 2014, 150, $193-198$. [CrossRef]

7. Da Silva, P.D.M.; De Lima, L.S.; Caetano, I.K.; Torres, Y.R. Comparative analysis of the volatile composition of honeys from Brazilian stingless bees by static headspace GC-MS. Food Res. Int. 2017, 102, 536-543. [CrossRef]

8. Obistioiu, D.; Cristina, R.T.; Schmerold, I.; Chizzola, R.; Stolze, K.; Nichita, I.; Chiurciu, V. Chemical characterization by GC-MS and in vitro activity against Candida albicans of volatile fractions prepared from Artemisia dracunculus, Artemisia abrotanum, Artemisia absinthium and Artemisia vulgaris. Chem. Cent. J. 2014, 8, 6. [CrossRef]

9. Saeidi, K.; Moosavi, M.; Lorigooini, Z.; Maggi, F. Chemical characterization of the essential oil compositions and antioxidant activity from Iranian populations of Achillea wilhelmsii K. Koch. Ind. Crop. Prod. 2018, 112, 274-280. [CrossRef]

10. Song, L.; Wu, J.; Li, F.; Peng, S.; Chen, B. Different responses of invasive and native species to elevated $\mathrm{CO}_{2}$ concentration. Acta Oecol. 2009, 35, 128-135. [CrossRef]

11. Lin, R.J.; Chen, C.Y.; Lo, W.L. Cytotoxic activity of Ipomoea cairica. Nat. Prod. Res. 2008, 22, 747-753. [CrossRef] [PubMed]

12. Yin, Y.Q.; Wang, J.S.; Luo, J.G.; Kong, L.Y. Novel acylated lipo-oligosaccharides from the tubers of Ipomoea batatas. Carbohyd. Res. 2009, 344, 466-473. [CrossRef] [PubMed]

13. Thomas, T.G.; Rao, S.; Lal, S. Mosquito larvicidal properties of essential oil of an indigenous plant, Ipomoea cairica Linn. Jpn. J. Infect. Dis. 2004, 57, 176-177. [PubMed]

14. Meira, M.; Da Silva, E.P.; David, J.M.; David, J.P. Review of the genus Ipomoea: chemistry and biological activities. Rev. Bras. Farmacogn. 2012, 22, 682-713. [CrossRef]

15. Li, J.H.; Pan, J.T.; Yin, Y.Q. Two novel resin glycosides isolated from Ipomoea cairica with $\alpha$-glucosides inhibitory activity. Chin. J. Nat. Med. 2016, 14, 227-231. [PubMed]

16. Yu, B.; Luo, J.; Wang, J.; Zhang, D.; Yu, S.; Kong, L. Pentasaccharide resin glycosides from Ipomoea cairica and their cytotoxic activities. Phytochemistry 2013, 95, 421-427. [CrossRef] [PubMed]

17. Lin, Z.; Chen, L.; Zhang, W. Peroxidase from Ipomoea cairica (L) SW. Isolation, purification and some properties. Process Biochem. 1996, 31, 443-448. 
18. Ishak, A.R.; Dom, N.C.; Hussain, H.; Sabri, N.H. Biolarvacidal potential of Ipomoea Cairica extracts against key Dengue vevtors. Procedia Soc. Behav. Sci. 2014, 153, 180-188. [CrossRef]

19. Samuel, L.; Lalrotluanga, R.; Muthukumaran, R.B.; Gurusubramanian, G.; Senthilkumar, N. Larvicidal activity of Ipomoea cairica (L) Sweet and Ageratina adenophora (Spreng.) King \& H. Rob. plant extracts against arboviral and filarial vector, Culex quinquefasciatus Say (Diptera: Culicidae). Exp. Parasitol. 2014, 141, 112-121. [PubMed]

20. Ferreira, A.A.; Amaral, F.A.; Duarte, I.D.G.; Oliveira, P.M.; Alves, R.B.; Silveira, D.; Azevedo, A.O.; Raslan, D.S.; Castro, M.S.A. Antinociceptive effect from Ipomoea cairica extract. J. Ethnopharmacol. 2006, 105, 148-153. [CrossRef] [PubMed]

21. Tulukcu, E.; Cebi, N.; Sagdic, O. Chemical Fingerprinting of Seeds of Some Salvia Species in Turkey by Using GC-MS and FTIR. Foods 2019, 8, 118. [CrossRef]

22. Nagyová, S.; Tölgyessy, P. Validation Including Uncertainty Estimation of a GC-MS/MS Method for Determination of Selected Halogenated Priority Substances in Fish Using Rapid and Efficient Lipid Removing Sample Preparation. Foods 2019, 8, 101. [CrossRef] [PubMed]

23. Sitaramaraju, Y.; Van Hul, A.; Wolfs, K.; Van Schepdael, A.; Hoogmartens, J.; Adams, E. Static headspace gas chromatography of (semi-) volatile drugs in pharmaceuticals for topical use. J. Pharmaceut. Biomed. 2008, 47, 834-840. [CrossRef] [PubMed]

24. Tian, J.; Rustum, A. Development and validation of a fast static headspace GC method for determination of residual solvents in permethrin. J. Pharmaceut. Biomed. 2016, 128, 408-415. [CrossRef] [PubMed]

25. Varona-Torres, E.; Carlton, D.D.; Hildenbrand, Z.L.; Schug, K.A. Matrix-effect-free determination of BTEX in variable soil compositions using room temperature ionic liquid co-solvents in static headspace gas chromatography mass spectrometry. Anal. Chim. Acta. 2018, 1021, 41-50. [CrossRef]

26. D’Autry, W.; Zheng, C.; Bugalama, J.; Wolfs, K.; Hoogmartens, J.; Adams, E.; Wang, B.; Van Schepdael, A. Liquid paraffin as new dilution medium for the analysis of high boiling point residual solvents with static headspace-gas chromatography. J. Pharmaceut. Biomed. 2011, 55, 1017-1023. [CrossRef]

27. Wang, M.; Fang, S.; Liang, X.R. Natural deep eutectic solvents as eco-friendly and sustainable dilution medium for the determination of residual organic solvents in pharmaceuticals with static headspace-gas chromatography. J. Pharmaceut. Biomed. Anal. 2018, 158, 262-268. [CrossRef]

28. Dai, Y.; Van Spronsen, J.; Witkamp, G.J.; Verpoorte, R.; Choi, Y.H. Natural deep eutectic solvents as new potential media for green technology. Anal. Chim. Acta. 2013, 766, 61-68. [CrossRef]

29. Zhang, Q.; De Oliveira Vigier, K.; Royer, S.; Jerome, F. Deep eutectic solvents: Syntheses, properties and applications. Chem. Soc. Re. 2012, 41, 7108-7146. [CrossRef]

30. Yoo, D.E.; Jeong, K.M.; Han, S.Y.; Kim, E.M.; Jin, Y.; Lee, J. Deep eutectic solvent-based valorization of spent coffee grounds. Food Chem. 2018, 255, 357-364. [CrossRef]

31. Pereira, F.P.; Namiesnik, J. Ionic liquids and deep eutectic mixtures: sustainable solvents for extraction processes. ChemSusChem 2014, 7, 1784-1800. [CrossRef] [PubMed]

32. Jeong, K.M.; Jin, Y.; Yoo, D.E.; Han, S.Y.; Kim, E.M.; Lee, J. One-step sample preparation for convenient examination of volatile monoterpenes and phenolic compounds in peppermint leaves using deep eutectic solvents. Food Chem. 2018, 251, 69-76. [CrossRef] [PubMed]

33. Fraige, K.; Arrua, R.D.; Sutton, A.T.; Funari, C.S.; Cavalheiro, A.J.; Hilder, E.F.; Da Silva Bolzani, V. Using natural deep eutectic solvents for the extraction of metabolites in Byrsonima intermedia leaves. J. Sep. Sci. 2019, 42, 591-597. [CrossRef]

34. Malaeke, H.; Housaindokht, M.R.; Monhemi, H.; Izadyar, M. Deep eutectic solvent as an efficient molecular liquid for lignin solubilization and wood delignification. J. Mol. Liq. 2018, 263, 193-199. [CrossRef]

35. Ni, M.; Sun, T.; Zhang, L.; Liu, Y.; Xu, M.; Jiang, Y. Relationship study of partition coefficients between ionic liquid and headspace for organic solvents by HS-GC. J. Chromatogr. B 2014, 945, 60-67. [CrossRef] [PubMed]

36. Fang, S.; Zuo, X.B.; Xu, X.J.; Ren, D.H. Density, viscosity and excess molar volume of binary mixtures of tri- $n$-octylamine + diluents ( $n$-heptane, $n$-octane, $n$-nonane, and $n$-decane) at various temperatures. J. Chem. Thermodyn. 2014, 68, 281-287. [CrossRef]

37. Duan, L.; Dou, L.L.; Guo, L.; Li, P.; Liu, E.H. Comprehensive Evaluation of Deep Eutectic Solvents in Extraction of Bioactive Natural Products. ACS Sustain. Chem. Eng. 2016, 4, 2405-2411. [CrossRef]

38. Dai, Y.; Witkamp, G.J.; Verpoorte, R.; Choi, Y.H. Tailoring properties of natural deep eutectic solvents with water to facilitate their application. Food Chem. 2015, 187, 14-19. [CrossRef] 
39. Kim, S.; Koo, I.; Wei, X.L.; Zhang, X. A method of finding optimal weight factors for compound identification in gas chromatography-mass spectrometry. Bioinformatics 2012, 28, 1158-1163. [CrossRef]

40. Koo, I.; Kim, S.; Zhang, X. Comparative analysis of mass spectral matching-based compound identification in gas chromatography-mass spectrometry. J. Chromatogr. A 2013, 1298, 132-138. [CrossRef]

41. Lee, H.; Finckbeiner, S.; Yu, J.S.; Wiemer, D.F.; Eisner, T.; Attygalle, A.B. Characterization of (E, E)-farnesol and its fatty acid esters from anal scent glands of nutria (Myocasgor coypus) by gas chromatography-mass spectrometry and gas chromatography-infrared spectrometry. J. Chromatogr. A 2007, 1165, 136-143. [CrossRef] [PubMed]

42. Kooa, I.; Shia, X.; Kimb, S.; Zhanga, X. iMatch2: Compound identification using retention index for analysis of gas chromatography-mass spectrometry data. J. Chromatogr. A 2014, 1337, 202-210. [CrossRef] [PubMed]

43. Yu, X.; Xu, M.; Li, N.; Li, Z.; Li, H.; Shao, S.; Zou, K.; Zou, L. $\beta$-elemene inhibits tumor-promoting effect of M2 macrophages in lung cancer. Biochem. Bioph. Res. Commun. 2017, 490, 514-520. [CrossRef] [PubMed]

44. Wu, W.; Liu, F.; Davis, R.W. Engineering Escherichia coli for the production of terpene mixture enriched in caryophyllene and caryophyllene alcohol as potential aviation fuel compounds. Metab. Eng. Commun. 2018, 6, 13-21. [CrossRef] [PubMed]

45. Ngamprasertsith, S.; Menwa, J.; Sawangkeaw, R. Caryophyllene oxide extraction from lemon basil (Ocimum citriodorum Vis.) straw by hydrodistillation and supercritical $\mathrm{CO}_{2}$. J. Supercrit. Fluid. 2018, 138, 1-6. [CrossRef]

46. Varsha, K.K.; Devendra, L.; Shilpa, G.; Priya, S.; Pandey, A.; Nampoothiri, K.M. 2,4-Di-tert-butyl phenol as the antifungal, antioxidant bioactive purified from a newly isolated Lactococcus sp. Int. J. Food Microbiol. 2015, 211, 44-50. [CrossRef] [PubMed]

(C) 2019 by the authors. Licensee MDPI, Basel, Switzerland. This article is an open access article distributed under the terms and conditions of the Creative Commons Attribution (CC BY) license (http://creativecommons.org/licenses/by/4.0/). 